\title{
Improving of Temperature Susceptibility of Asphalt 60/70 using Synthesized Reactive Rubber Nanoparticles for use in Different Climate \\ Ragab AA ${ }^{1 *}$, Reem K Farag ${ }^{1}$, Usama F Kandil', El-Shafie M'1 , Saleh AMM ${ }^{1}$ and Ahmed F El-Kafrawy ${ }^{2}$
}

${ }^{1}$ Department of Petroleum Applications, Egyptian Petroleum Research Institute (EPRI), Cairo, Egypt

${ }^{2}$ Department of Organic Chemistry, Faculty of Science, Ain- Shams University, Cairo, Egypt

\begin{abstract}
The use of reactive polymers as modifiers for asphalt appears promising. Asphalt penetration grade 60/70 cannot be used in coating applications for its long drying time at ordinary temperature and for its brittleness at very cold temperature. This material is very cheap as compared to blown asphalt that usually used in industrial applications. This study aims to use reactive polymers in modification of soft asphalt to produce very specific asphaltic material for use in infrastructure applications especially coating instead of highly expensive materials. The new asphaltic material is low cost and has high quality performance at low temperature.

To achieve the aim of study, RRNP was used as additive to modify asphalt in percentages of $3,5,7$ and $10 \%$ w/w. The prepared RRNP was then tested for their particles size using DLS and TEM, SEM, 1HNMR. RRNP was used to modify the thermo mechanical properties of asphalt via forming chemical bond, and the changing in mechanical and thermal properties of the mixes as well as the storage stability were studied. Also, the morphology (SEM), thermal characterization (TGA), Dynamic mechanical analysis (DMA), rheological tests, while, the prepared coatings were applied to carbon steel panel and tested for bending, Abarsion test and impact test were detected. Overall, the results show that the chosen modifiers are the best so far in the modification of soft asphalt to suit the industrial applications in different climate conditions.
\end{abstract}

Keywords: Asphalt; Reactive rubber; Dynamic mechanical; Infrastructure

\section{Introduction}

Nowadays, polymer modified asphalt have been used with success at different applications [1]. Asphalt modifiers can be classified according to reactivity with asphalt binder into: passive modifiers which not contain active groups (e.g. LDPE, HDPE and tire rubber) [2]. Asphalt has been modified with polymers that can be classified into three groups. One of the groups that is thermoplastics which do not react with asphalt such as high-density polyethylene (HDPE), metallocene catalyzed high density polyethylene (m-HDPE), and (LDPE) [3]. These polymers provide toughness and rigidity to asphalt reducing deformation under load. Passive polymers do not react with asphalt and only physical crosslinks (steric stabilization) can retard a phase separation [4]. The most common polymers have been used in asphalt modification include (SBS) copolymer, (SBR), tire rubber, (EVA), polyethylene, and others [5-7]. Plastomers and elastomers are physically dispersed into asphalt, and swollen in asphaltic continuous phase, with improved mechanical properties due to formation of weak physical interactions between the polymer and asphalt components. However, these polymers have very low compatibility with asphalt, and easy to occur phase separation.

When adding a functionalized polymer to asphalt, specific interactions between asphalt and the polymers, such as hydrogen bonding can take place. Also, some other forms of chemical reactions could take place between the reactive groups of the matrix (asphalt and polymers). When functionalized polymers are blended, reactive or chemical compatibility can occur, giving high chance the formation of in-situ copolymers as a result to the chemical reaction during processing [8]. A good example of a polymer that reacts with asphalt, is a product commercially produced by Dupont names, Elvaloy AM. This type of copolymer forms a polymer-linked-asphalt system with improved performance properties.

The improvement of asphalt properties had been studied [9] with using Liquid Natural Rubber (LNR) via dissolving rubber into fluxing oil, by various kinds of natural rubber latex [10], natural rubber powder, or powdered reclaimed rubber [11]. Poor distribution of the polymers into the asphalt matrix is the main challenge facing this type from asphalt modifications. It is critical to overcome such critical drawback if rubber to be used in modifying asphalt.

Improved properties of natural rubber for certain applications can be made via chemical modifications. This is possible because of the presence of double bonds $(\mathrm{C}=\mathrm{C})$ in the natural rubber polymer chain that act as simple olefin. The epoxidized natural rubber ENR is an important chemical rubber modification product. The use of epoxidized natural rubber (ENR) as a modifier was began since 1980s [12]. ENR formed from reaction between natural rubber and proxy formic acid [12]. This material has a high strength because of its ability to bear strain crystallization, and high glass transition temperature. These good properties increased oil resistance, enhanced adhesion properties, damping and reduced gas permeation $[13,14]$. ENR when using as modifier able to increase the complex viscosity, dynamic properties of the blends [15]. ENR preparation details are reported in the study by Yu et al. and Okwu et al. [16-18]. Possibility of epoxidation natural rubber was stated that $1 \%$ to $90 \%$, however considered commercial of ENR products ENR-10, ENR-25 and ENR-50 were 3 types only. These are where the integers designate 10, 25 and 50 mole $\%$ of epoxide incorporated into the natural rubber chain respectively. Chemical modification of natural rubber enhanced its properties. Thus, ENR also display properties that are the same as a specialty elastomer such as decrement in air permeability, which is comparable to a butyl rubber and increment in oil resistance, which is comparable to acrylonitrile

*Corresponding author: Ragab AA, Department of Petroleum Applications, Egyptian Petroleum Research Institute (EPRI), Cairo, Egypt, Tel: +20 2 22745902; E-mail: chemragab83@yahoo.com

Received July 05, 2017; Accepted October 03, 2017; Published October 09, 2017

Citation: Ragab AA, Farag RK, Kandil UF, El-Shafie M, Saleh AMM, et al. (2017) Improving of Temperature Susceptibility of Asphalt 60/70 using Synthesized Reactive Rubber Nanoparticles for use in Different Climate. J Civil Environ Eng 7: 285. doi: 10.4172/2165-784X.1000285

Copyright: @ 2017 Ragab AA, et al. This is an open-access article distributed under the terms of the Creative Commons Attribution License, which permits unrestricted use, distribution, and reproduction in any medium, provided the original author and source are credited. 
butadiene rubber (ABR) A part from being renewable, the choice of ENR-50 is based on its structural composition of 50 mole $\%$ of $\mathrm{C}=\mathrm{C}$ and epoxide groups respectively, which are randomly distributed in its polymer chain providing sites for physical or chemical interaction.

This research aims to improvement of temperature susceptibility of asphalt 60/70 (which is not used in different climate applications) via modification of asphalt using reactive rubber nanoparticles to produce an attractive material has low cost and superior characteristics as compared to oxidized asphalt that commercially used in coating and roofing application. The produced material increase the application fields of asphalt 60/70 at wide range of temperatures.

\section{Experimental Methods}

\section{Materials}

Asphalt cement: asphalt cement of penetration grade (60/70) produced by Elnasr Petroleum Company (APC) in Suez, Egypt.

Chemicals: Natural rubber (poly isoprene (NR; Narobien Toluene and Methanol, Hydrochloric acid, crosslinker divinylbenzene. palmitic acid, benzoyl peroxideas (BPO) and potassium hydroxide $\mathrm{KOH}$.

\section{Experimental procedure}

Test methods for characterization of virgin and modified samples: All samples were tested in the following methods: Penetration (ASTMD5, 2005), Kinematic viscosity of Asphalt (ASTM D 2170, 2001), Specific gravity of asphalt (ASTM D2726, 2008), Flash point (ASTM D92, 2001), Softening point (ASTM D36, 1995), Ductility of bituminous materials (ASTM D113, 1999), Fourier Transform Infrared Spectroscopy (FTIR). (ASTM E1252, 1998) Infrared spectra of the studied virgin asphalt and their modified blends were recorded via FTIR spectrophotometer (Model 960 Mooog, ATI Mattson Infinity Series, USA). The spectra of all studied samples were measured in the range of $4000-400 \mathrm{~cm}^{-1}$ by summing 32 scans at $4 \mathrm{~cm}^{-1}$ resolution and 32 background scans, TGA (ASTM E1131, 2003) TGA analyses was carried out using SDT Q600 Simultaneous TGA analyzer to test the thermal properties and thermal stability of the virgin asphalt, polymers and their modified blends in the temperature range of 25 to $7000 \mathrm{C}$ and a heating rate of $10^{\circ} \mathrm{C} / \mathrm{min}$ under dynamic nitrogen gas, Scanning electron microscope (SEM) [19]. The SEM photographs of asphalt virgins and their modified blends have been determined by using Scanning electron microscopy (SEM; Philip), Rheology of Asphalt using Brookfield viscometer (ASTM D4287, 1994). Shear Stress and Viscosity at given Shear Rates using Brookfield DVIII Ultra Programmable Rheometer, and Dynamic Mechanical Analysis (DMA) [20]. Dynamic mechanical analysis was performed by Triton Technology- TTDMA which determines storage modulus, loss modulus and $\tan \delta$. Disk-formed specimens with $10 \mathrm{~mm}$ dia. and $3 \mathrm{~mm}$ thickness were tested at room temperature and $1 \mathrm{~Hz}$ frequency.

Synthesis of reactive rubber nano-particles (epoxidized SBR): Synthesis or rubber nano-particle as shown in Figure 1 carried out as follow: dissolving $5.0 \mathrm{~g}$ of natural rubber (NR), $50 \mathrm{~mL}$ toluene and $5 \%(\mathrm{wt} / \mathrm{wt}$ ) of palmitic acid, $5 \%$ to $7 \%(\mathrm{wt} / \mathrm{wt})$ of divinylbenzene and about $1.0 \%$ (wt/wt) of benzoyl peroxide in beaker. The backer contents are poured slowly into flask to a vigorously stirring solution of $\mathrm{KOH}$ in $100 \mathrm{~mL}$ of deionized $\mathrm{H}_{2} \mathrm{O}$ such that the final emulsion has a $\mathrm{pH}$ slightly alkaline. strong stirring for $30 \mathrm{~min}$, then the emulsion was homogenized by sonification for $30 \mathrm{~min}$ in an ultrasonic processor homogenizer operating at 300 bar under an atmosphere of nitrogen. Put the flask under $\mathrm{N}_{2}$ purging for $30 \mathrm{~min}$ before rising the temperature to $90^{\circ} \mathrm{C}$. the time of this process ranging from 2 to 6 hours, depending on the viscosity of the samples and consequently on the molecular weight of

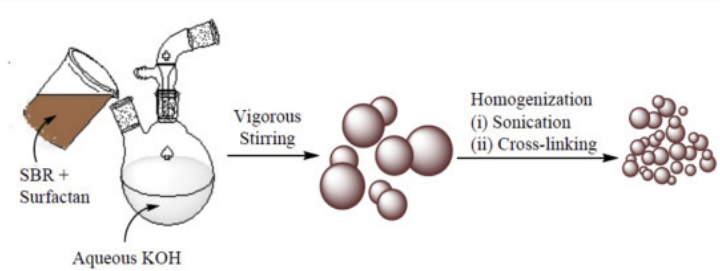

Figure 1: Synthesis of rubber nano-particles.

(I)

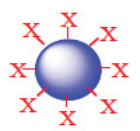

O: Cross-linked polyolefin rubber particle $\mathrm{X}$ : Reactive functional group

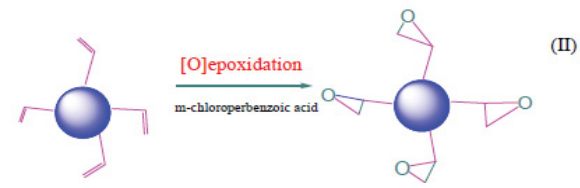

Figure 2: Reactive rubber nano particle preparation: (I) Cross linking (II) Toughened with epoxy groups.

the used rubber. The product was coagulated by $\mathrm{HCl} /$ methanol, redispersed in chloroform and precipitated with methanol to remove the surfactant before an overnight drying under vacuum was conducted. During the emulsification process; colloidal samples were isolated by syringing in time intervals for the determination of the particle size distribution and volume-average diameters of the particles by Dynamic Light-Scattering analyzer. Figure 2 shows the steps of epoxidized SBR. The reactive rubber particles are represented by Formula (I), in which the poly isoprene particle is a cross-linked polyolefin elastomer $\left(\mathrm{Tg}<-60^{\circ} \mathrm{C}\right)$ and a sub-micro (nano) particle size. Some reactive groups denoting as (X) can be introduced via the remaining double bonds located on or near the surface include a broad choice of desirable functional groups such as; $\mathrm{OH}, \mathrm{COOH}, \mathrm{NH}_{2}$, epoxide, anhydride, styrene, borane, silane, and mixtures, which can react with various rigid materials during the reactive blending, extrusion, and polymerization processes. During the cross-linking reaction to form stable polyisoprene rubber particles; the internal double bonds units of rubber react with each other via radical addition reaction by help of the cross linking agent. However, most of external double bonds units on the surfaces are much more difficult to find each other and are remained on the surfaces, which are very valuable in reactions with function groups which adding through the subsequent steps [21].

Characterization of rubber nano-particle (RNP) and reactive rubber nano-particles (epoxidized SBR)

${ }^{1}$ H-NMR spectroscopic analysis: Both samples of RNP and RRNP were analyzed using ${ }^{1} \mathrm{HNMR}$ spectroscopic for determination of absence and present of double bonds in samples. Bruker AM-300 spectrometer with the DISNMR software recorded the spectrum at room temperature. Preparation of the NMR samples by dissolving in d-chloroform [22].

Scanning electron microscope (SEM): Scanning electron microscope examine bulk morphology in the films using a Topcon International Scientific Instruments ISI-SX-40 with secondary electron imaging. Samples for SEM analysis were prepared from films cryofractured in liquid $\mathrm{N}_{2}$. Samples were mounted on an aluminum stub and coated using gold to form a conductive coating.

Transmission electron microscopy (TEM): Preparation of the samples by dipping the grid in a dilute prepared sample solution 
followed by evaporating the solvent which affords a very thin film for TEM analysis.

TEM was performed at $120 \mathrm{kv}$ using model JEOL JEM 1200 EXII equipped with a video camera, a Gatan Bioscan 792 camera and a high resolution Tietz F224 camera and a prism light element detector [23].

Dynamic light scattering (DLS) measurements: Coulter LS 230 using for determination of particle size distributions and volumeaverage diameters of the RNP and PMAs samples. Moreover, the range of detectable particle sizes is extended to the submicron region (lower size limit: $50 \mathrm{~nm}$ of diameter) [24].

\section{Preparation of modified asphalt samples}

The calculated amount of asphalt $60 / 70$ was heated up to $180^{\circ} \mathrm{C} \pm$ $5^{\circ} \mathrm{C}$ in a suitable can until it become pourable. Gradually addition of both of (RRNP) and (RNP) in percent as 3\%, 5\%, 7\% and 10\% (of the weight of the base asphalt) to asphalt in rate as $5 \mathrm{gr} / \mathrm{min}$ at $2000 \mathrm{rpm}$ mixer for $2 \mathrm{hrs}$ until the blends became essentially homogenous. Shell method [25] test using for tested compatibility the prepared samples. Figure 3 show that good dispersion of the resulting core-shell rubber particles in the asphalt matrix.

\section{Evaluation of modified asphalt samples as coating materials}

Mandrel test (ASTM D522) tested the prepared samples which were applied on steel sheets and after complete curing for cracking resistance, Drop Weight Impact Testing (ASTM D5628/ 1996), Abrasion resistance of organic coatings (ASTM D 4060, 1995) and the abrasion test instrument used in this study was a mode of ABRASER 325 and Drying time (D 1640, 2003).

\section{Results and Discussion}

\section{Synthesis of functional rubber nanoparticles}

This class of functional rubber nanoparticles is represented by Formula III (Figure 4), which show that cross-linked styrene-cobutadiene (SBR). The reactive double bond moieties located on or near the surface, can easily be transferred to reactive functional group. Rubber

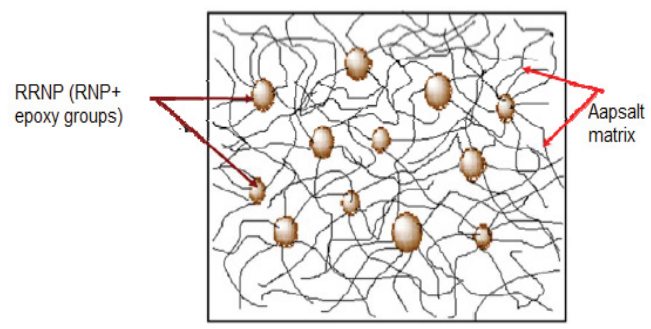

Figure 3: Schematic representation of a toughened virgin asphalt sample with epoxidized SBR.

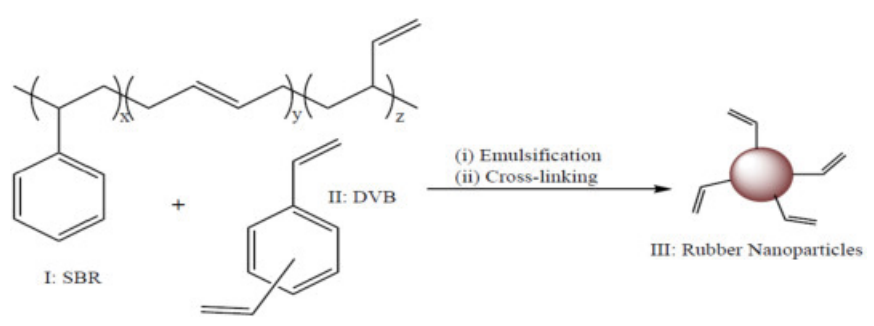

Figure 4: Synthesis of functional rubber nanoparticles.

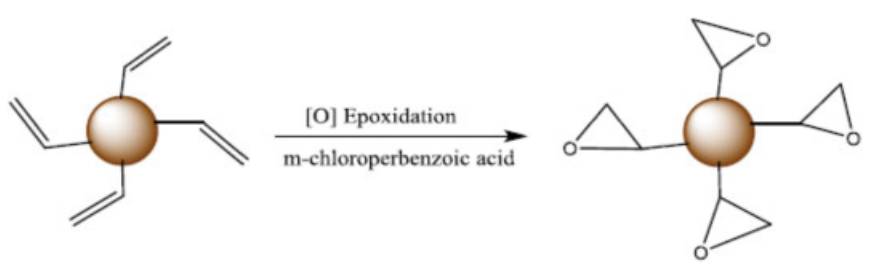

Figure 5: Epoxidation of rubber nanoparticles.

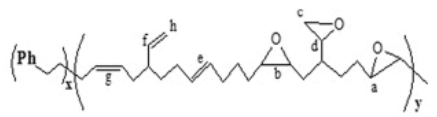

(a)

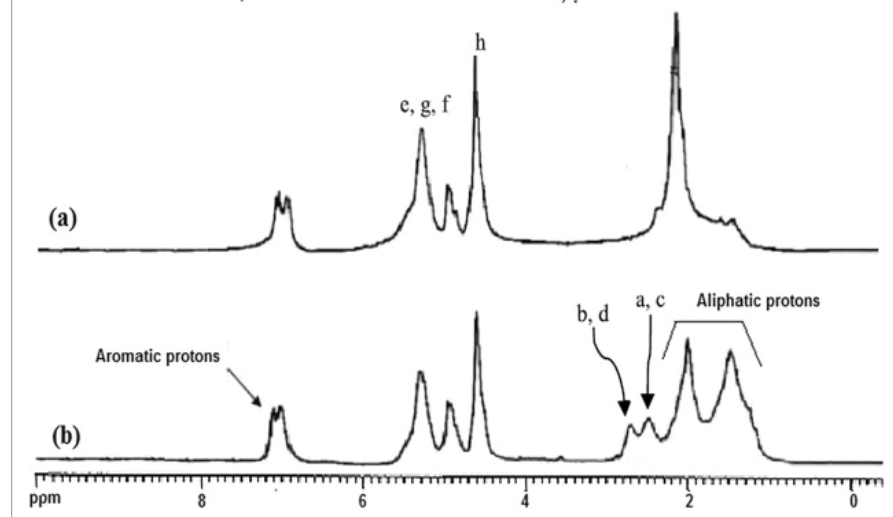

Figure 6: ${ }^{1} \mathrm{H}$ NMR (a) SBR (b) Epoxidized rubber nanoparticles.

nanoparticles (III) has advantage is the existence of a controlled quantity of double bond Allow them to be active if they interact with effective in many chemical reactions, including cross-linking, functionalization, polymerization, etc.

During the cross-linking reaction to form stable styrene-cobutadiene(SBR) rubber nanoparticles; the internal double bonds units react with each other by the enhancement of the cross-linking agent (divinylbenzene DVB) via radical addition reaction. Consequently, the double bond units on the surfaces or near it, remained on the surfaces due to more difficult to find each other. This will be available to the subsequent functionalization reactions.

\section{Synthesis of reactive rubber nanoparticles}

Reaction of Formula III with m-chloroperbenzoic acid produces the rubber core (epoxidized SBR); represented by the formula shown in Figure 5.

\section{Characterization of epoxy nanocomposites}

${ }^{1}$ H NMR spectroscopy: The epoxidized rubber nanoparticles was characterized by $1 \mathrm{H}$ NMR spectrum where the formation of epoxy groups is assured by the appearance of two new signals corresponding to the protons of the epoxy group with the reduction in area of the signal of vinyl double bond protons. Figure 6 shows the ${ }^{1} \mathrm{H}$ NMR spectra of (a) SBR and (b) epoxidized SBR rubber nanoparticles. The ${ }^{1} \mathrm{H}$ NMR spectrum of SBR (Figure 6a) shows a signal at $\delta=4.9 \mathrm{ppm}$ for two terminally vinylic hydrogens SBR demonstrates a broad signal at $7.0 \mathrm{ppm}$, which denotes the five hydrogen atoms of the phenyl ring and a signal at $\delta=5.4 \mathrm{ppm}$ that is attributed to trans- and cis-1,4 hydrogens. In addition, the ${ }^{1} \mathrm{H}$ NMR spectrum of epoxidized SBR (Figure $6 \mathrm{~b}$ ) shows two new signals at 2.45 and $2.7 \mathrm{ppm}$, which can be attributed to the cis- and trans-epoxy groups respectively [26]. From Figures $6 \mathrm{a}$ and $6 \mathrm{~b}$ spectra, appearance of two new signals is attributed to the epoxy ring 
Citation: Ragab AA, Farag RK, Kandil UF, El-Shafie M, Saleh AMM, et al. (2017) Improving of Temperature Susceptibility of Asphalt 60/70 using Synthesized Reactive Rubber Nanoparticles for use in Different Climate. J Civil Environ Eng 7: 285. doi: 10.4172/2165-784X.1000285

Page 4 of 9

protons formed via SBR reaction with $m$-chloroperbenzoic acid with the reduction in signal area of the vinylic protons.

FTIR spectroscopy: The FT-IR spectra of SBR and epoxidized SBR
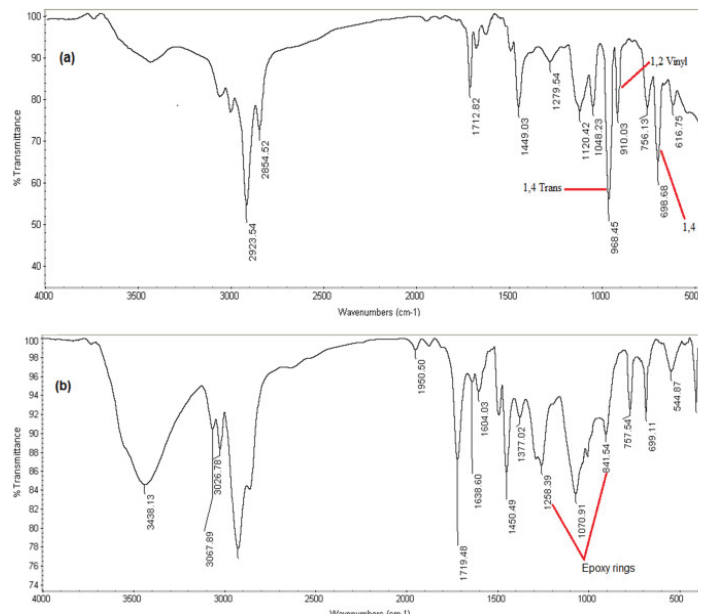

Figure 7: (a) FTIR of SBR (b) Epoxidized SBR nanoparticles.

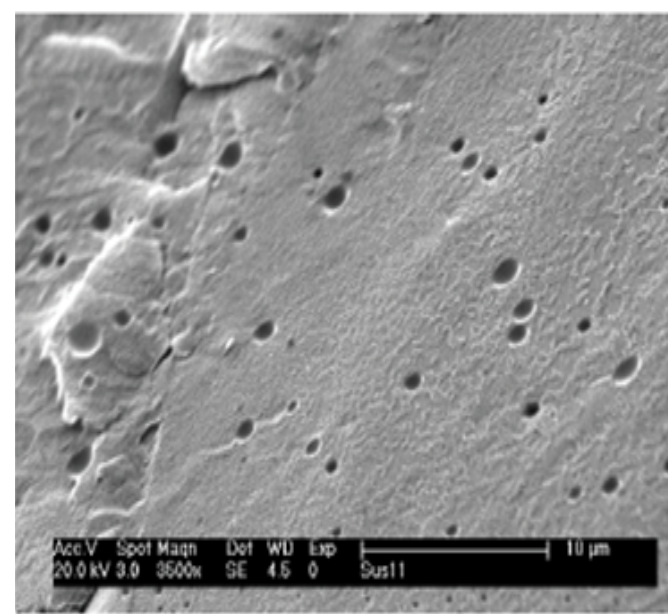

Figure 8a: SEM micrographs of a simple blend between unfunctionalized rubber nanoparticles and asphalt.

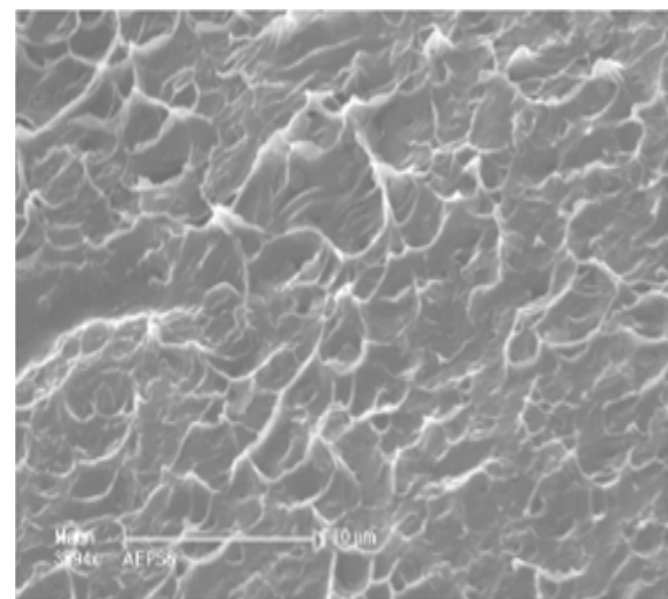

Figure 8b: SEM micrographs of the reactive blend between epoxidized particles and asphalt.

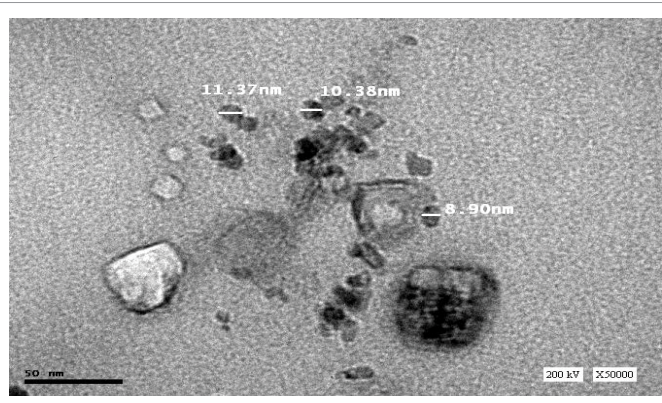

Figure 9: TEM micrograph of asphalt toughened with $5 \%$ epoxidized SBR.

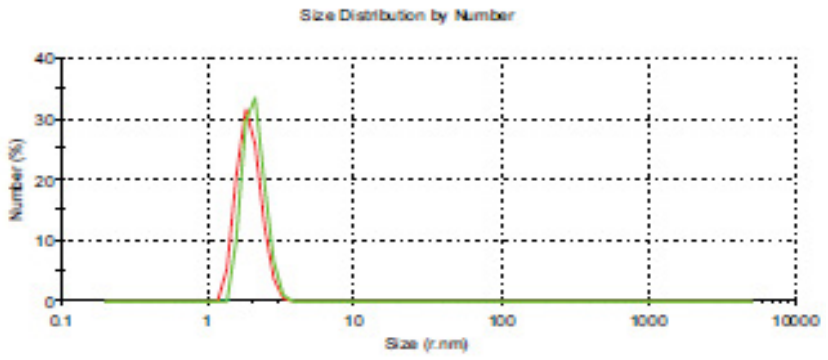

Figure 10: DLS of epoxidized SBR.

are shown in Figures $7 \mathrm{a}$ and $7 \mathrm{~b}$, respectively. Figure $7 \mathrm{a}$ showed a band at $910 \mathrm{~cm}^{-1}$ to 1,2 -vinyl double bonds, a band at $969 \mathrm{~cm}^{-1}$ to 1,4 -trans, respectively and a band at $699 \mathrm{~cm}^{-1}$ that is related to 1,4 -cis. In the FTIR spectrum of epoxidized SBR (Figure 7b) the bonds of stretching and contracting in phase of all epoxy rings were observed at about 1258 and $842 \mathrm{~cm}^{-1}[26]$.

\section{Epoxidized SBR/asphalt nanocomposite}

After functionalization, the epoxy groups of epoxidized SBR reacted with asphalt components so, has good dispersion into the asphalt matrix as represented in Figure 3. This was assured by the morphological study of the formed nanocomposites using Scanning Electron Microscope (SEM) and Transmission Electron Microscope (TEM).

Scanning electron microscopy (SEM): The epoxy functional group located on the surface of rubber nanoparticles enhances the reactivity of these particles during the curing reaction of epoxy. Figure 8 shows the SEM micrographs of RNP (Figure 8-left) with RRNP/asphalt reactive blend (Figure 8-right).

It is clear from these photos that; in a simple blend, there are a lot of concave holes and convex particles in the fracture surface which indicates the weakness of adhesion between the rubber nanoparticles and the asphalt. But in case of using RRNP the holes disappeared. This is due to chemical reaction between epoxy groups and asphalt components. This reaction enhances the adhesive force between the asphalt and the particles and exceeds the matrix cohesive force.

Transmission electron microscopy (TEM): As shown in Figure 9 the cross-linked rubber nanoparticles distributed uniformly in the asphalt matrix. This is an essential requirement for toughening mechanism. Consequently, rubber nanoparticles (RRNP) are homogeneously dispersion in the asphalt matrix as a result for chemical interactions as shown in Figure 3.

DLS measurement: Figure 10 shows DLS test results. Volumeaverage diameters and particle size distributions of the RNP samples were determined. The curve shows range from 2 to 8 for RNP that the rubber nanoparticles size distribution. 
Citation: Ragab AA, Farag RK, Kandil UF, El-Shafie M, Saleh AMM, et al. (2017) Improving of Temperature Susceptibility of Asphalt 60/70 using Synthesized Reactive Rubber Nanoparticles for use in Different Climate. J Civil Environ Eng 7: 285. doi: 10.4172/2165-784X.1000285

Page 5 of 9

\begin{tabular}{|c|c|c|c|c|c|}
\hline \multirow{2}{*}{ Characteristics } & \multirow{2}{*}{$A C$} & \multicolumn{4}{|c|}{ PMAs with epoxidized SBR } \\
\hline & & $3 \%$ & $5 \%$ & $7 \%$ & $10 \%$ \\
\hline $\begin{array}{c}\text { Penetration (at } 25^{\circ} \mathrm{C}, 100 \\
\text { g, } 5 \mathrm{~s}) 0.1 \mathrm{~mm}\end{array}$ & 62 & 42 & 27 & 17 & 7 \\
\hline $\begin{array}{c}\text { Softening point (ring and } \\
\text { ball) }\left({ }^{\circ} \mathrm{C}\right)\end{array}$ & 50.6 & 56 & 72 & 80 & 88 \\
\hline Specific gravity (at $25^{\circ} \mathrm{C}$ ) & 1.02 & 1.027 & 1.038 & 1.042 & 1.06 \\
\hline $\begin{array}{l}\text { Dynamic viscosity (at } \\
80^{\circ} \mathrm{C} \text { ) c.P }\end{array}$ & 599186 & 2065993 & 2961639 & 3254821 & 3776172 \\
\hline $\begin{array}{c}\text { Dynamic viscosity (at } \\
130^{\circ} \mathrm{C} \text { ) c.P }\end{array}$ & 1499.68 & 67605 & 177277 & 248025 & 485787 \\
\hline Penetration index & -0.51 & -0.21 & 2.83 & 3.12 & 4.3 \\
\hline
\end{tabular}

Table 1: Physical characteristics of PMAs using epoxidized SBR.

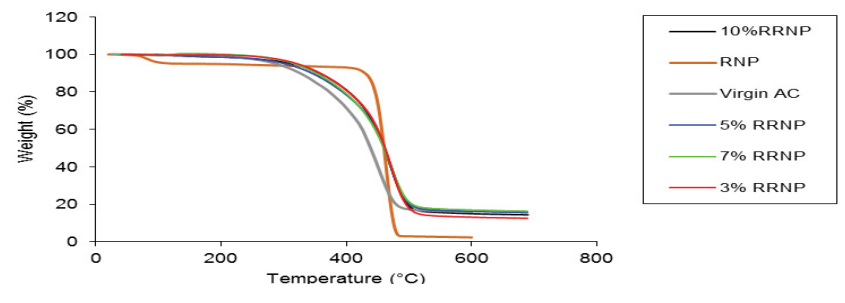

Figure 11: TGA of PMA using epoxidized SBR (RRNP).

\section{Characterization of polymer modified asphalt samples (PMAs)}

PMA samples were prepared as previously mentioned using $3 \%$, $5 \%, 7 \%$ and $10 \%$ epoxidized SBR. The characteristics of all samples will be detected as follows:

From Table 1 the properties and performance of asphalt 60/70 dramatically changes with the polymer modification.

Physical characteristics modified samples: Hardness of modified using epoxidized SBR increases with increasing the epoxidized SBR content from $3 \mathrm{wt} \%$ to $10 \mathrm{wt} \%$ more than virgin asphalt sample. Also, it is noticed from Table 1 that, hardness is remarkable more than that of virgin asphalt.

With, increasing the epoxidized SBR ratio from $3 \mathrm{wt} \%$ to $10 \mathrm{wt} \%$ penetration of PMAs decreased in percentages of 32.3, 56.45, 72.6 and $88.7 \%$, while softening point increased in percentages of $10.87,42.29$, 58.1 and $73.9 \%$ respectively with addition of epoxidized SBR as 3,5, 7 and $10 \%$. Also, the dynamic viscosity at $60^{\circ} \mathrm{C}$ increased in percentages of $473.0,546.4,678.5$ and 1036.5 and at $130^{\circ} \mathrm{C}$ increased in percentages of $8.6,68.24,196.53$ and 221.64 respectively. While the penetration index increased from -0.51 to $-0.21,2.83,3.18$ and 4.3 respectively as well as the specific gravity increased in the same manner.

This is due to the properties and the presence of reactive groups which react with asphalt components to form chemical bond. Epoxy group react reacts with carboxylic groups present in asphaltenes, thus lead to formation of an ester link which improves storage stability and prevent phase separation. Chemical network could theoretically form if the asphaltene molecule, or micelle, contains more than one carboxylic group. Ether bond possible to formed when the epoxy ring open by a hydroxyl group. Moreover, an intermolecular cross-linking reaction can take place once a epoxidized SBR ring has been opened by any of the above-mentioned reactions or a water molecule, and a hydroxyl group has been formed on the polymer main chain [4]. Polymer network can be formed not necessarily involving asphalt molecules. Detection of the real nature of chemical bonds formed during the curing period is so difficult due to the extremely complex chemical nature and composition of asphalts, it. Considering that the curing time is generally 24 or $48 \mathrm{~h}$ at $160^{\circ} \mathrm{C}$ to $180^{\circ} \mathrm{C}$, it is reasonable to assume that to some extent all the proposed reactions occur. It is important; the polymer amount has to be chosen very carefully when asphalt is modified by epoxidized SBR, because an excessive quantity leads to the formation of an infusible and insoluble asphalt gel. Therefore, either by the presence of inter polymer reactions or by asphaltene bridges, a network can form when functionalized polymers are added to asphalt. So, reactive polymers generally added in ratios from $1.5 \%$ to $7 \%$ by weight. Due to the chemical nature of the bonds that are formed between polymer / polymer or/and polymer asphalt chains molecules, the reaction must be stopped when the cross-linking polymer consists of a distribution of clusters, swelled by asphalt.

Temperature susceptibility of modified samples: From Table 1 with comparing to virgin AC the P.I values also, increased from -0.51 for virgin $\mathrm{AC}$ to $-0.21 \& 2.83$ and 3.12 and 4.32 for $3 \%$ to $10 \%$ of epoxidized SBR content respectively. Also, rubber materials the increase the resistance of asphalt samples to cracking at low temperature.

The penetration index of all modified asphalt samples from Table 1 the PI proved a rather powerful indicator for classifying asphalt rheological behavior, and it was observed that blown asphalt had typically $\mathrm{PI}<1$ when straight-run asphalt had $-1>\mathrm{PI}>+1$. Only very susceptible materials such as coal tar gave $\mathrm{PI}>-1$. Therefore, PI was thought to be an important indicator of asphalt type, with $\mathrm{PI}<2$ being indicative of a gel asphalt whereas PI 0 being typical of a sol. In general, PI varies between -2.6 and 8 when including all types of asphalt (including blown ones), but typically lies between -2 and +2 for paving grades asphalt. Solvent deasphalted asphalt could give PI values between -2 and 2, based on the exact process used (especially type of solvent and yield. Still, negative values were more frequent and deasphalted asphalt are generally considered more susceptible than straightrun ones. Van der Poel showed that if asphalt has the same PI will have similar rheological master curves. Since a mathematical model turned out to be quite difficult to propose, Van der Poel developed a nomograph from which the complex (or creep) modulus at whatever temperature and frequency (or time) can be predicted for given asphalt, knowing only its PI, Ring, and ball softening temperature. This device still gives acceptable values.

TGA analysis: Figure 11 show TGA curves for prepared reactive rubber nanoparticle (epoxidized SBR) and virgin asphalt 60/70. RNP showing decomposition stage from $425^{\circ} \mathrm{C}$ to $487^{\circ} \mathrm{C}$ with mass loss $97.72 \%$ while, $\mathrm{AC}$ which has the decomposition stage as previously mentioned from 290 to $490^{\circ} \mathrm{C}$ with mass loss of $84.17 \%$ but PMAs samples showed a very similar thermal behavior when compared to virgin AC. As shown, in case of using RRNP modifier in percentages $3 \%$ and $5 \%$, the complete weight loss decreased from $97.72 \%$ to $84.26 \%$ and to $84.2 \%$ respectively.

SEM photos of PMAs: Figure 12 shows that samples have a good compatibility. On the other hand, the micrograph of the RRNP shows no convex particles or concave holes on their fracture surfaces. The uniform fracture surface means consistent failure in the continuous asphalt matrix. From data PMAs using epoxidized SBR (RRNP) show good compatibility this is due to strong interaction between asphalt and epoxy group found in case of using RRNP.

\section{Rheology test}

Viscosity and temperature: As shown in Figure 13 the viscosity of PMAs samples are highly remarkable decrease as compared to the unmodified sample. This is due to presence of rubber particle which cause improvement in rheological properties of virgin asphalt. dynamic viscosity decreases in case of using RRNP3 at temperature $60^{\circ} \mathrm{C}$ in 
Citation: Ragab AA, Farag RK, Kandil UF, El-Shafie M, Saleh AMM, et al. (2017) Improving of Temperature Susceptibility of Asphalt 60/70 using Synthesized Reactive Rubber Nanoparticles for use in Different Climate. J Civil Environ Eng 7: 285. doi: 10.4172/2165-784X.1000285

percentages of $3,5,7$ and $10 \% \mathrm{w} / \mathrm{w}$ in percentages of $300,350,360$ and $600 \%$ respectively while at $130^{\circ} \mathrm{C}$ dynamic viscosity decreases in percentages $47,50,52$ and 53 . The high differences is due to presence of epoxy group in RRNP which interact with asphalt to form very strong network causes the asphalt to become highly viscous.

Shear rate and shear stress: The shear rate- shear stress of asphalt and its modified samples at $60^{\circ} \mathrm{C}$ and $130^{\circ} \mathrm{C}$ (for an example) is detected at the following subsection:

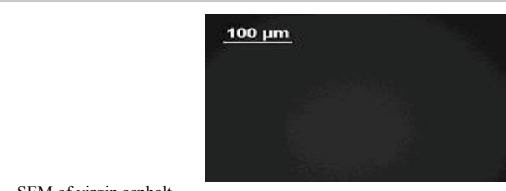

SEM of virgin asphalt

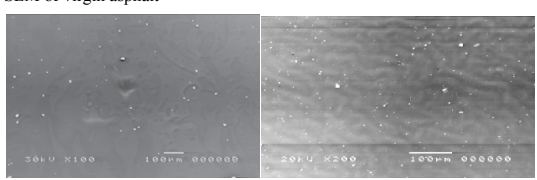

SEM of PMA using 3\% RRNP

SEM of PMA using $5 \%$ RRNP

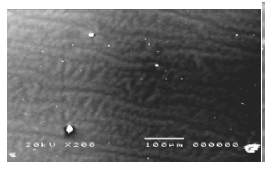

$\because-3$

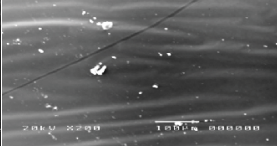

SEM of PMA using $10 \%$ RRNP

Figure 12: SEM of PMAs using RRNP

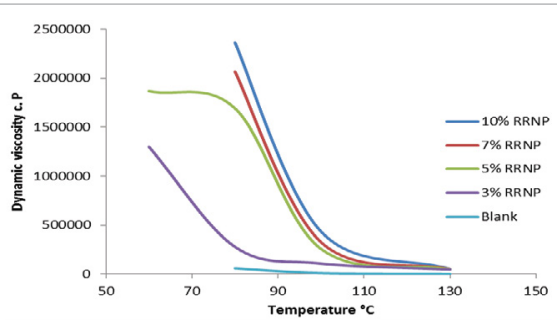

Figure 13: Dynamic vicosity with temperature of PMA using RRNP.

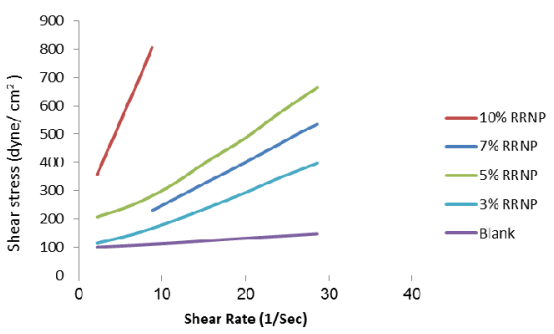

Figure 14: Shear stress shear rate curves of PMA using RRNP at $80^{\circ} \mathrm{C}$.

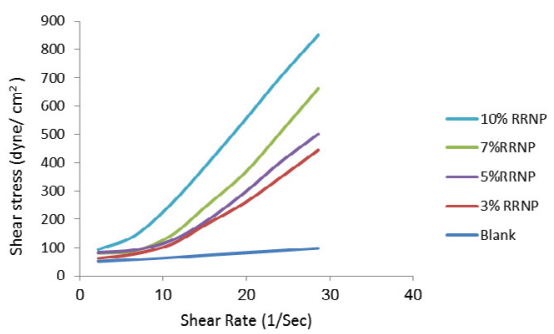

Figure 15: Shear stress shear rate curves of PMA using RRNP at $130^{\circ} \mathrm{C}$.

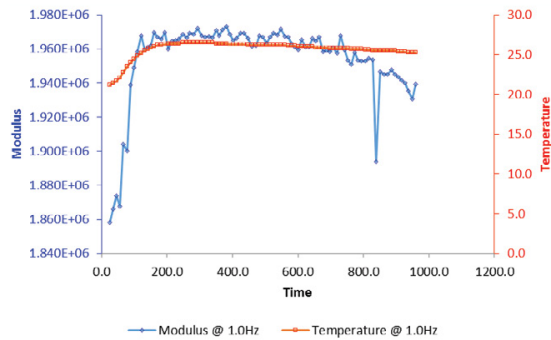

Figure 16a: Modulus and Temperature vs. Time for $3 \%$ RRNP.

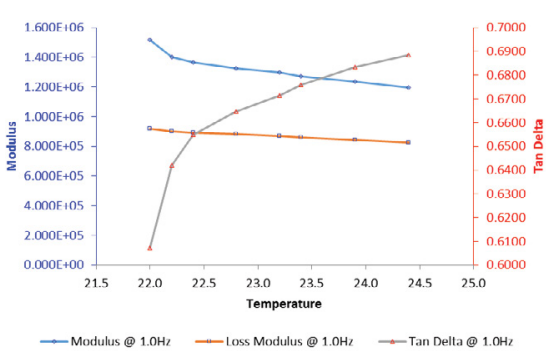

Figure 16b: Dynamic and Tan Dlta vs. temperature for $3 \%$ RRNP.

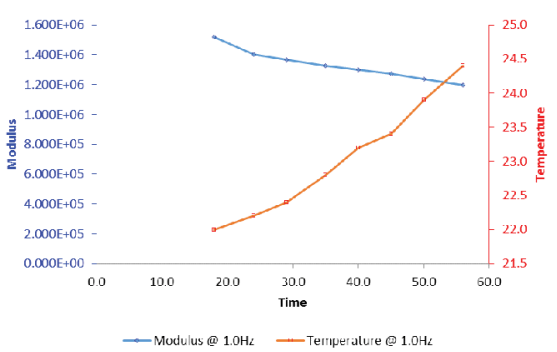

Figure 17a: Modulus and temperature vs. time for $5 \%$ RRNP.

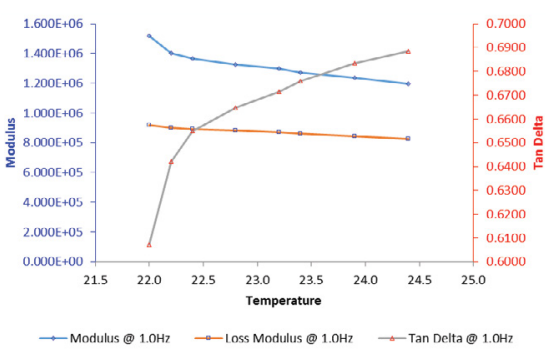

Figure 17b: Dynamic and tan dlta vs. temperature for $5 \%$ RRNP.

As shown in Figures 14 and 15 it is noticed that the elasticity modulus of PMAs increase with increasing the polymer addition level in order of 3, 5, 7 and 10\% w/w for RRNP, the elasticity modulus is remarkable highly increased. This is due to that RRNP functional groups formed an ester link with carboxylic groups present in asphaltenes. This bond should prevent phase separation and improve storage stability. Moreover, if the asphaltene molecule, or micelle, contains more than one carboxylic group, a chemical network could theoretically form. Other reactions are possible between the RRNP group and the functional groups present in asphalts. As previously mentioned, the hydroxyl group can be opened epoxy ring to form an ether bond or by an amine group. Moreover, once a RRNP ring has been opened by any of the above-mentioned reactions or a water molecule, and hydroxyl 
Citation: Ragab AA, Farag RK, Kandil UF, El-Shafie M, Saleh AMM, et al. (2017) Improving of Temperature Susceptibility of Asphalt 60/70 using Synthesized Reactive Rubber Nanoparticles for use in Different Climate. J Civil Environ Eng 7: 285. doi: 10.4172/2165-784X.1000285

Page 7 of 9

group has been formed on the polymer main chain, an intermolecular cross-linking reaction can take place. This would lead to the formation of a polymer network not necessarily involving asphalt molecules [4].

Dynamic mechanical analysis (DMA): DMA is commonly used to study curing materials as this process involves a dramatic increase in modulus values. Coatings can see many frequencies and temperatures in their life service. In this study DMA is conducted at ambient temperature and a frequency value a $0.1 \mathrm{~Hz}$ for an example of the dynamic mechanical response of the coating as shown in Figures $16 \mathrm{a}$ and 16b to Figures 19a and 19b) in all PMAs with RRNP tan (delta) is $<1$ which mean that these samples more elastic than the others. Strong intermolecular interactions are responsible for the higher storage modulus. When the sample starts to cure, modulus grows faster because the cross linking reaction. When modulus is equal to loss

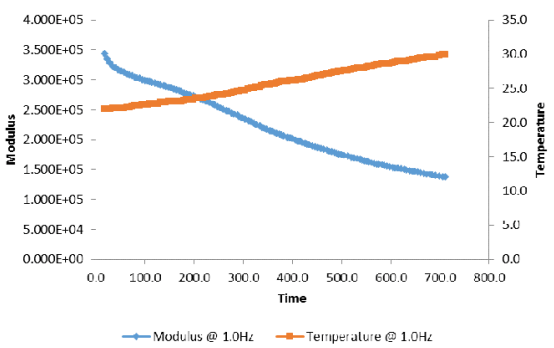

Figure 18a: Modulus and temperature vs. time for $7 \%$ RRNP.

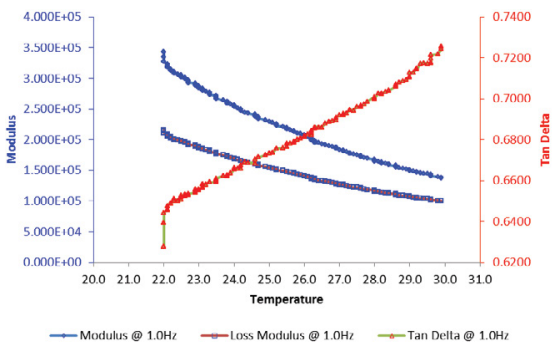

Figure 18b: Dynamic and tan delta vs. temperature for $7 \%$ RRNP.

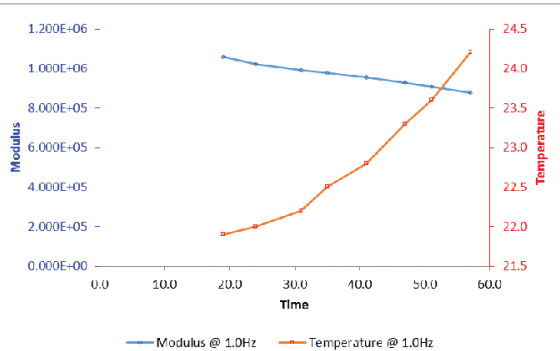

Figure 19a: Modulus and temperature vs. time for $10 \%$ RRNP.

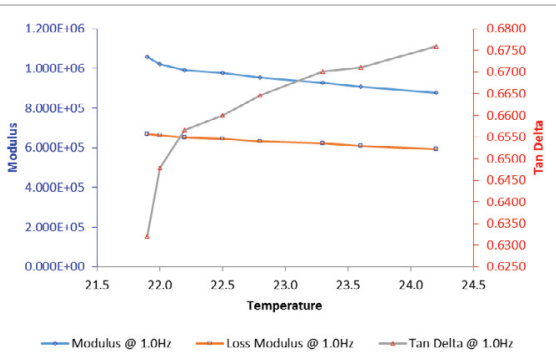

Figure 19b: Dynamic and tan delta vs. temperature for $10 \%$ RRNP.

\begin{tabular}{|c|c|c|}
\hline Sample type & $\mathbf{5 . 5} \mathbf{J}$ & $\mathbf{7 . 5} \mathbf{J}$ \\
\hline $\mathrm{AC}$ & Failed & Failed \\
\hline $\mathrm{OA}$ & Failed & Failed \\
\hline \multicolumn{2}{|c|}{ PMAs using } \\
\hline $3 \%$ RRNP & Pass & Failed \\
\hline $5 \%$ RRNP & Pass & Failed \\
\hline $7 \%$ RRNP & Pass & Pass \\
\hline $10 \%$ RRNP & Pass & Pass \\
\hline
\end{tabular}

Table 2: Results of impact test of PMAs Samples Using RNP and RRNP.

\begin{tabular}{|c|c|c|c|c|}
\hline Sample type & wt. loss \% (gm) & wt. loss (gm) & wt. after (gm) & wt. before (gm) \\
\hline AC & 5.7 & 4.6 & 74.7674 & 79.3674 \\
\hline OA & 2.8 & 2.2 & 76.3243 & 78.5243 \\
\hline 3\% RRNP & 1.08 & 0.8612 & 78.2305 & 79.0917 \\
\hline $5 \%$ RRNP & 1.04 & 0.7431 & 70.6994 & 71.4425 \\
\hline 7\% RRNP & 0.94 & 0.6694 & 70.2466 & 70.916 \\
\hline 10\% RRNP & 0.87 & 0.6396 & 72.874 & 73.5136 \\
\hline
\end{tabular}

Table 3: Abrasion resistance of PMAs with RRNP samples comparing with AC and $\mathrm{OA}$.

modulus ( $\tan$ delta $=1$, loss tangent), that this is the "gel point" but at that frequency and temperature. In addition, when both curves are flat in time, then reaction has finished. Also, from figures slightly decrease in the modulus this is referring to increasing stability and resistance for deformation of PMAs and has high storage stability modulus.

\section{Evaluation of PMAs samples as coating materials}

Drop weight impact testing: Data in Table 2 illustrate that all PMAs using RRNP show no damage visually at an impact equals one kilogram drops from higher equal $55 \mathrm{~cm}$ to give an impact equal $5.5 \mathrm{~J}$. This is due to that PMAs are tougher than AC and OA so the ability to resist damage are higher. Also, PMA using $7 \%$ and $10 \%$ of RRNP are passing and no damage seen visually at impact equal $7.5 \mathrm{~J}$. This may be explained by that theses samples become very tough and completely flexible as a result of the chemical constituents of the rubber additive and as well as its ability to form chemical network with asphalt.

Abrasion resistance of PMAs: Results in Table 3 illustrate final mass loss value of AC virgin equals 5 to 7 times that value detected for PMAs samples. In addition, the final mass loss value of OA (Oxidized asphalt) which commonly used equals 2.8 to 3.3 times of that detected for PMAs samples. The above-mentioned results show that PMAs samples using RRNP become more resistant for conditions such as loads, scratching material than the commonly used asphalt (OA) and AC 60/70. This is due to strong reaction between epoxy ring and asphalt molecule forming tougher samples. Also, increase the content of the additives in the modified asphalt samples cause the weight loss to decrease. This indicated that PMAs samples using RRNP become more resistant for abrasion than the commonly used asphalt (OA) and AC 60/70.

Mandrel bending test: This test method shows ability in rating attached coatings for resist cracking and elongation. The test detects the flexibility of coatings on flexible substrates Based on ASTM D522 and from Figures 20a and 20b we can find that $\mathrm{AC}$ (freeze at $0^{\circ} \mathrm{C}$ ) and $\mathrm{OA}$ samples when elongated with Mandrel bending tester the cracks appear on the panel. From Figures 21a-21e the modified sample, complete flexible with increasing RRNP content from 3 to $10 \%$, and no cracks appear. This is due to the flexibility nature of rubber itself.

Drying time test: From Table 4 it is found that the drying time is highly decreased in case of using RRNP comparing to the virgin asphalt sample. This is attributed to the nature of modifier added itself. From data the drying time decreases in $61.1,69.4,72.2$ and $75 \%$ in case of 
Citation: Ragab AA, Farag RK, Kandil UF, El-Shafie M, Saleh AMM, et al. (2017) Improving of Temperature Susceptibility of Asphalt 60/70 using Synthesized Reactive Rubber Nanoparticles for use in Different Climate. J Civil Environ Eng 7: 285. doi: 10.4172/2165-784X.1000285

Page 8 of 9

using 3, 5, 7 and 10\% RRNP. The presence of epoxy ring in case of using RRNP accelerates the drying time. The epoxy groups as previously mentioned react with some functional groups of asphalt to form strong chemical network. Finally, using RNP and RRNP decrease the drying time of the prepared samples and became suitable for use as coating materials.

\section{Conclusion}

This research aims to use reactive polymers in modification of asphalt to produce very specific asphaltic material for use in infrastructure applications especially coating instead of highly expensive materials. The new asphaltic material is low cost and has high quality performance at low temperature. To achieve the aim of study, reactive polymers were used as additives to modify asphalt 60/70. The additives were rubber nanoparticle (RNP) and reactive rubber nano-particle (RRNP) in percentages of 3, 5, 7 and $10 \mathrm{wt} \%$. The results of study concluded that:

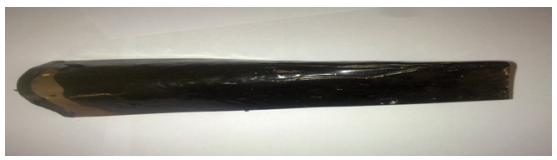

Figure 20a: Mandrel bend testing panel of virgin AC

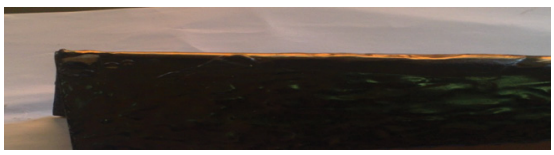

Figure 20b: Mandrel bend testing panel of Oxidized asphalt (OA).

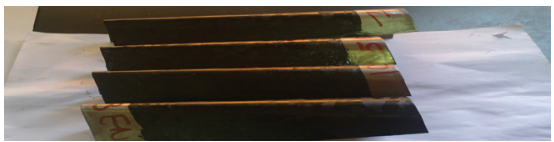

Figure 21a: Mandrel bend testing panel of asphalt modified with RRNP.

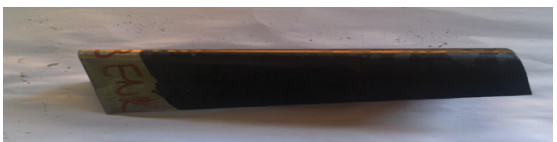

Figure 21b: Mandrel bend testing panel of asphalt modified with $3 \%$ RRNP.

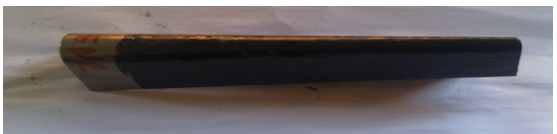

Figure 21c: Mandrel bend testing panel of asphalt modified with $5 \%$ RRNP.

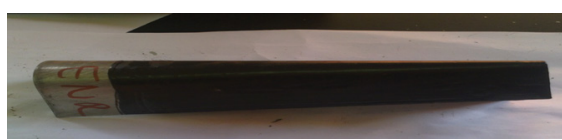

Figure 21d: Mandrel bend testing panel of asphalt modified with 7\% RRNP.

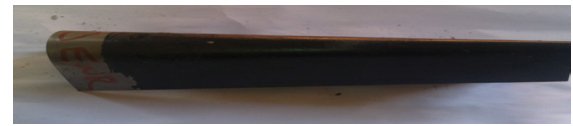

Figure 21e: Mandrel bend testing panel of asphalt modified with $10 \%$ RRNP.

\begin{tabular}{|c|c|}
\hline Sample type & Curing time hours \\
\hline AC & 72 \\
\hline OA & No time \\
\hline $3 \%$ RRNP & 28 \\
\hline $5 \%$ RRNP & 22 \\
\hline $7 \%$ RRNP & 20 \\
\hline $10 \%$ RRNP & 18 \\
\hline
\end{tabular}

Table 4: Curing time for PMAs using RRNP samples.

1.Mixes showed a significant improvement in the workability under different temperatures due to reducing temperature susceptibility.

2. The PMAs samples have desired thermo- dynamical properties, such as reduced plastic flow at high temperatures, increased shear modulus and and/or increased resistance to thermal fracture at low temperatures.

3. The modification using reactive polymers, which can form chemical network with asphalt components improved storage stability and enhanced in-service performance.

4. RNP and RRNP epoxy groups' opened and reacted with functional groups in asphaltene molecule as $-\mathrm{OH}$ and $\mathrm{COOH}$ to form ester.

5. Active groups present in polymer added can react with asphalt component or with polymer groups itself to form strong chemical bonds. Subsequently, phase separation is prevented, which in turn enhances the material's consistency, and decreases oxidative ageing.

6. PMAs using RRNP show improved properties more than that using RNP due to its high reactivity for epoxy ring presence.

7. The prepared coating using PMAs become completely flexible at very low temperatures.

8. PMAs high resistant to abrasion with compared with AC and OA which means the prepared PMAs coating sample become more resistant for bad conditions.

9. PMAs have low drying time with compared to soft asphalt and acceptable for use under variable environmental conditions more than the oxidized asphalt which common use for these applications.

10. PMAs exhibits improvement in physical and rheological properties to be valid for using in infrastructure applications. Finally, this thesis produces an attractive solution for using the available local $60 / 70$ asphalt in infrastructure applications under different climate.

\section{References}

1. King G (1999) Additives in asphalt. J Assoc Asphalt Paving Technol A 68: 3269.

2. Luo WQ, Chen JC (2011) Preparation and properties of bitumen modified by EVA graft copolymer. Constr Build Mater 25: 1830-1835.

3. Pérez-Lepe A, Martínez-Boza FJ, Gallegos C (2007) High temperature stability of different polymer modified bitumens: A rheological evaluation. J Appl Polym Sci 103: 1166-1174.

4. Polacco G, Filippi S (2014) Vulcanization accelerators as alternative to elemental sulfur to produce storage stable SBS modified asphalts. Constr Build Mater 58: 94-100.

5. Lu X, Isacsson U (2001) Modification of road bitumens with thermoplastic polymers. Polym Test 20: 77-86.

6. Morrison GR, Lee JK, Hesp SAM (1994) Chlorinated polyolefins for asphalt binder modification. J Appl Polym Sci 54: 231-40.

7. Boutevin B, Pietrasanta Y, Robin J (1989) Bitumen polymer blends for coatings applied to roads and public constructions. Prog Org Coat 17: 221-249. 
Citation: Ragab AA, Farag RK, Kandil UF, El-Shafie M, Saleh AMM, et al. (2017) Improving of Temperature Susceptibility of Asphalt 60/70 using Synthesized Reactive Rubber Nanoparticles for use in Different Climate. J Civil Environ Eng 7: 285. doi: 10.4172/2165-784X.1000285

Page 9 of 9

8. Hayner RE (1999) Sulfur in oil asphalt and polymer composition and process. Marathon Ashland Petroleum, LLC.

9. Nair NR, Mathew NM, Thomas S, Chatterjee P, Siddqui MA (1992) Physical and rheological characteristics of liquid natural rubber modified bitumen. J Appl Polym Sci 68: 53-61.

10. Fernando MJ, Nadarajah M (1992) Use of natural rubber latex in road construction. Polymer modified asphalt binders. American Society for Testing and Material, Philadelphia, USA.

11. Shelburne TE, Sheppe RL (1950) Field experiments with powdered rubber in bituminous road construction. Rubber Age 66: 531-358.

12. Yoksan $\mathrm{R}$ (2008) Epoxidized natural rubber for adhesive applications. Kasetsart $\mathrm{J}$ (Nat Sci) 42: 325-332.

13. Gelling IR (1991) Epoxidised natural rubber. J Nat Rubber 6: 184-205.

14. Ismail H, Hairunezam HM (2001) The effect of a compatibilizer on curing characteristics, mechanical properties and oil resistance of styrene butadiene rubber/epoxidized natural rubber blends. Eur Polym J 37: 39-44.

15. Zhang C, Wang W, Huang Y, Pan Y, Jiang L, et al. (2013) Thermal, mechanical and rheological properties of polylactide toughened by expoxidized natural rubber. Mater Des 45: 198-205.

16. Yu H, Sidong L, Zheng P (1999) Preparation and study of epoxidized natural rubber. J Therm Anal Calorim 58: 293-299.

17. Okwu UN, Okieimen FE (2001) Preparation and properties of thioglycollic acid modified epoxidised natural rubber and its blends with natural rubber. Eur Polym J 37: 2253-2258.
18. Tanrattanakul V, Wattanathai B, Tiangjunya A, Muhamud P (2003) In situ epoxidized natural rubber: Improved oil resistance of natural rubber. J App Polym Sci 90: 261-269.

19. Qin Q, Farrar MJ, Pauli AT, Adams JJ (2014) Morphology, thermal analysis and rheology of Sasobit modified warm mix asphalt binders. Fuel 115: 416-425.

20. Menard K (2008) Dynamic mechanical analysis: A practical introduction (2nd edn). CRC Press, USA.

21. Kandil U, Chung TC (2005) Polymer star-brushes from reactive and crosslinked ethylene-based rubber particles; synthesis and applications. Polymer Preprints 46: $68-69$

22. Ahmed MA, Kandila UF, Shakera NO, Hashem AI (2015) The overall effect of reactive rubber nanoparticles and nano clay on the mechanical properties of epoxy resin. J Radiat Res Appl Sci 8: 549-561.

23. Aboubakra SH, Kandil UF, Taha MR (2014) Creep of epoxy-clay nanocomposite adhesive at the FRP interface: A multi-scale investigation. Int J Adhes Adhes 54: 1-12.

24. Jenkins F, White H (1976) Fundamentals of optics. (4th edn). McGraw-Hill Inc. USA.

25. Read J, Whiteoak D (2003) The shell bitumen handbook. (5th edn) Thomas Telford Publishing, London, UK.

26. Rajabi FH, Nikje MMA, Taslimipour T (2010) Epoxidation of styrene-butadiene rubber (SBR) using in situ generated dimethyldioxirane (DMD): Characterization and kinetic study. Des Monomers Polym 13: 535-546. 